\title{
Comparison of Electronic and Workshop Teaching Methods on Midwives Knowledge about Pregnant Women Caring and Attitude Regarding to E-Learning in Kerman
}

\author{
Pooran Hadidi, ${ }^{1}$ Sakineh Sabzevari, ${ }^{2,}$ and Ramin Homayoni Zand ${ }^{3}$ \\ ${ }^{1}$ Medical Education Student, Medical Education Department, Medical Education Faculty, Shahid Beheshti University of Medical Sciences and Health Services, Tehran, IR Iran \\ ${ }^{2} \mathrm{PhD}$ of Nursing Education, Assistant Professor, Medical Education Development Center, Kerman University of Medical Sciences and Health Services, Kerman, IR Iran \\ ${ }^{3}$ General Practitioner, Medical Education Department, Medical Education Faculty, Shahid Beheshti University of Medical Sciences and Health Services, Tehran, IR Iran \\ "Corresponding author: Sakineh Sabzevari, PhD of Nursing Education, Assistant Professor, Medical Education Development Center, Kerman University of Medical Sciences and \\ Health Services, Kerman, IR Iran. Tel: +98-3432332519, E-mail: s_sabzevari@kmu.ac.ir
}

Received 2015 July 25; Revised 2015 November 30; Accepted 2015 December 24.

\begin{abstract}
Introduction: Obstetricians and health personnel are the first and foremost personnel with direct patient contact. E-learning can be considered an appropriate method for the in-service training of the health personnel. Therefore, the present study was conducted aiming at an investigation on the efficacy of the two training methods of workshop and e-learning training on the level of knowledge of the obstetricians as well as their attitudes towards e-Learning.

Methods: This was a semi empirical study in which 66 obstetricians, working at health centers. The participants were randomly divided into two groups of workshop (33 subjects) and e-Learning training (33 subjects). Using knowledge and attitude questionnaire, the knowledge and attitude of the subjects in the two groups were measured and data was analyzed through paired and independent T-test employing SPSS version 18.

Results: No difference was observed between the knowledge pre-test scores of the two groups; and the post-test scores of the two groups showed an identical and significant increase. Furthermore, the difference between scores of attitude towards e-learning, before and after training ( $34.24 \pm 4.86$ and $36.76 \pm 6.36$, respectively) was statistically significant $(\mathrm{P}=0.04)$.

Conclusions: The results showed that both training methods increased the personnel knowledge level equally and that the attitudes of participants of the e-learning training group were more positive towards e-learning subsequent to the training. As a result, e-learning training method (especially in the form of training CDs) can be employed as a complement to workshop training and a modern method to be adopted for employee in-service training.
\end{abstract}

Keywords: E-learning, Workshop, Education, Knowledge, Attitude

\section{Introduction}

Effective learning is a result of proper training in appropriate environment using creative methods. Continuous improvement of teaching and learning methods has accelerated education, opening new horizons to the science (1). Teaching people is the most important duty of managers. Thus, one of the most important responsibilities of managers is helping personnel in improving professional abilities. In order to update the information, considering drastic changes in health care services, development and update of the educational system seems inevitable (2). Moreover, using computers is an essential part of today's human life in all societies. Education is also affected by this technology. One of the advantages of computer tools, like CDs, is providing educational services with appropriate cost. Also, this tool provides cost-effective and easy saving and transferring of information (3).

Investigations show that healthcare staff highly tends to participate in in-service training. However, many factors seriously challenge the access of these trainings, such as family problems, work fatigue, lack of motivation and lack of alternative staff (4). Self-learning methods enables learners to learn without having to leave their workplace on their own schedule and their preferred place. Selflearning, as an education method, includes individual activities in which the person learns without participating in conferences, seminars, and scheduled programs, on one's own interests and needs to improve knowledge and practical skills (5).

Fifth and seventh principles of the continuous medical education focus on "improvement of healthcare services as a priority of continuous education" and "applying proper educational methods", respectively. Participant's interests and needs, as one of the six important components of planning retraining, must be considered (6). One study showed that success in e-learning program, to a high extent, relies on the learner's fulfillment. This means that learners who 
are satisfied with the e-learning program are most likely to benefit the program (7).

A study was conducted by Sung et al. titled as "Combined training of drug management for new nurses; a combination of e-learning and face-to-face training in classroom" (8). The results indicated that training of drug management by e-learning, increases knowledge of drug management compared to classroom traditional training. Elearning greatly reduces lecture time and costs for repeating training programs. Although the initial costs of establishing e-learning programs are high, the method is costeffective in the long run and it can be used in nurses' resting time. Thus, e-learning can be practically used in nurses' workplace (8). A study was done by Zolfaghari et al. titled as "Effect of e-learning and lecture methods on learning mother and child health course for nursing students". In this semi-experimental study, all 32 students in their 3rd semester participated. During the first four weeks, classroom lecture method was applied. During the second four weeks, students continued the course by e-learning method. At the end, students' opinions were assessed using questionnaire. Results of this study showed that there is not a significant relationship between learning using the two methods. However, in the e-learning method, "independence" and "usability of method" was significantly higher. At the end, researchers concluded that lecture and e-learning methods have similar educational effects in mother and child health course for nursing students (9).

Given that nursery and healthcare personnel are in the first line of contact with people referring to healthcare service centers and play a major role in potentially under risk groups of the society, efforts must be made to improve their knowledge in order to reach positive results (5). Thus, considering lack of research regarding comparing e-learning with workshop training of the nursery personnel/and their views on workshop learning and also the importance of caring pregnant women in their pregnancy and reducing maternal mortality as a health development index, this study is aimed on comparing the effectiveness of e-learning and workshop training methods in caring pregnant women and obstetricians' personnel of Kerman healthcare centers views on e-learning methods.

\section{Methods}

This is a quantitative, analytical, interventional research. After filling sociological questionnaire gaining their consent, 71 obstetricians employed in Kerman healthcare centers participated in the study. Using random allocation (tossing, first in workshop training list and second in e-learning method), 35 were included in the workshop method and 36 in the e-learning method. Inclusion criteria was having a bachelor or associate degree of midwifery, having the responsibility of caring pregnant women in Kerman health clinics, and not having participated in retraining for diseases of kidney and urinary tract.

The knowledge questionnaire was the similar for the two groups prior to and after training and consisted of 24 multiple-choice questions. Validity of the questions was done by Lawsh and Mesik method. The questions were about educational objectives; content relationship and content coverage were determined. For scoring the questionnaire, score one was assigned to true answers and score zero was assigned to false or undefined answers. Maximums score was 24 and minimum was zero. To assess stability, the questionnaire was presented to 20 midwifery personnel of Afzalipour hospital and Chronbach's alpha was 0.85 . The attitude questionnaire contained 15 threechoice questions: I agree, I disagree, no idea scored 1,2,3, respectively. Minimum attitude score was 15 and maximum was 45 . Validity of the contents of the attitude questionnaire was confirmed by members of faculty. To assess stability, attitude questionnaire was filled by 20 midwives in Afzalipour hospital with Alpha of 0.97.

To provide content of the research, a handout in Microsoft Word format and slides in Microsoft PowerPoint format were prepared covering topics on kidney and urinary tract diseases related to pregnancy. In workshop method, the topics were presented by an instructor. In elearning method, the content was presented on a CD (in 2003 and 2007 formats for ease of use). A contact phone number was given to the subjects to contact in case of any problems using the CD.

Sociological questionnaire was filled in one session by all subjects. In this session, information regarding elearning and the objectives of the study was presented to subjects and their questions were answered. The draw was done afterwards to determine members of each group. Also, it was stated that filling the questionnaire indicated their consent on participating the study and each subject can exit during the study. A two-day workshop was held for workshop group with 15 days interval between the two sessions. In the first session, information regarding e-learning method was presented to subjects and pretest knowledge and attitude questionnaires were filled by participants. Training materials in CD was presented afterwards. Subjects participated the second session 15 days later. In this session, knowledge questionnaire (post-test) and attitude questionnaire were filled after the training. Ethical considerations were done in this study; the research was conducted by presenting an introduction letter from educational deputy of the center for research and development of Shahid Beheshti University of Medical Sci- 
ences to relevant authorities and gaining permission for elearning trainings and holding workshops in health center of Kerman, optional participating in the research, ensuring participants about the confidentiality of their information, non-obligatory use of first and last name and using code to compare before and after states of the two groups, appreciating the participants, and permitting participants to exit during study. SPSS version 18 was used to analyze data. Quantitative variables were presented by mean and standard deviation, and qualitative variables as frequency and percent. Statistical tests such as independent t-test to compare mean between the two groups and paired t-test to compare mean in each group. Descriptive statistics including frequency, frequency percentage, mean, and standard deviation. $(\mathrm{P}<0.05$, was considered as significance level).

\section{Results}

71 people participated study, 36 in e-learning group and 35 in workshop group ( 2 people from the workshop and 3 people from the e-learning method were excluded due to personal reasons). Results showed that participants of the groups were similar regarding sociological characteristics. No significant difference affecting the results was found (Table 1). Thus, it can be said that the results are most likely due to intervention.

Regarding personal characteristics, results showed that participants mean age was $37.20 \pm 5.45$ and job experience of $11.8 \pm 5.94,74.2$ percent of them were married and 75.8 percent had bachelor degree. Regarding using computer, most participants had low to moderate knowledge. Regarding interest to use e-learning, 84.8 percent of participants had moderate to high interest and all participants had no history of participating in e-learning programs. Paired t-test was used to assess the impact of workshop method on knowledge of participants. Since there was a significant difference in mean and standard deviation of scores pre and post-test $(14.12 \pm 2.51$ and $2.88 \pm 2.88$ and $\mathrm{P}<0.05$ ), it was concluded that e-learning affected participants' knowledge. Knowledge before and after training was compared between workshop and e-learning methods. Mean and standard deviation of pre-test scores (workshop group $15.06 \pm 3.4$ and e-learning group $14.12 \pm 2.51$ ) and post-test scores (workshop group $20.21 \pm 2.74$ and elearning group $20.88 \pm 2.88$ ) were very close. P values before and after intervention were 0.21 and 0.34 , respectively and no significant difference was found in mean knowledge before and after intervention between the two groups $(\mathrm{P}<0.001)$. Thus, the two methods had positive effects in increasing participants' knowledge (Table 2).

Mean score of attitude in e-learning before training (34.24 \pm 4.86$)$ and after training (36.76 \pm 6.36$)$ was com- pared using paired t-test and P value (0.04) was lower than significance level $(\mathrm{P}<0.05)$. Thus, e-learning affected the attitude of participants (Table 3).

Regarding other personal characteristics, no difference was found. Moreover, no relation was found between other personal characteristics with main variables.

\section{Conclusions}

This study compared the impact of workshop and elearning methods on knowledge and attitude of participants of the study. The results showed that both workshop and e-learning methods have impacts on increasing knowledge of participants and this impact was relatively similar. Regarding the impact of e-learning on attitude of participants after training, the results showed that elearning had positive impacts on participants' attitude.

According to the results, knowledge was similar in the two groups. Findings of current study are in line with Francescato et al. Fattahi Bafghi et al. Hugenholtz et al. Bahri et al. Barbaz and Zareiyan, Emrani et al. Vafamehr, and Zarif Sanaiey et al. studies (10-17). In these studies, either workshop or e-learning methods were compared with other methods such as lecturing, face to face (classroom), self-learning manual, problem solving,cooperative learning. The reason that their results are in line with the current study is that they stated that e-learning increased knowledge of participants even more than other training methods.

Results of current study showed that attitude of participants increased after intervention by the e-learning method. The reason of low scores before intervention can be due to lack of computer using skills in participants of current study and no history of participating in e-learning programs. Increase in attitude can be due to experiencing this method after intervention, decreasing stress of participants after facing the method, or providing training materials in CD. This enabled every user with low computer using skills to use the materials. Also, some features made this usable for adults such as: time and place flexibility, learning pace, learner's independence, and self-direction. Findings of the current study in this regard are in line with findings of Meyer, Al-Doub, LatifNejad Roudsari et al. (18-20). Subjects had no history of participating in similar trainings; also, low hardware equipment and appropriate environment for students and unfamiliarity of students made mentioned studies to be in line with the current study. In Borhani et al. study, participants had no history of participating in e-learning. After training and experiencing this method, their attitude to this method was more positive. The reason for this positive attitude after 
Table 1. Frequency of Demographic Variables ${ }^{\mathrm{a}}$

\begin{tabular}{|c|c|c|c|c|}
\hline Variable & & Workshop & Electronic & Total \\
\hline \multirow{2}{*}{ Marital status } & Single & $10(30.3)$ & $7(21.2)$ & $17(25.8)$ \\
\hline & Married & $23(69.7)$ & $26(78.7)$ & $49(74.2)$ \\
\hline \multirow{2}{*}{ Education level } & Technician & $7(21.2)$ & $9(27.3)$ & $16(24.2)$ \\
\hline & Bs & $26(78.8)$ & $24(72.7)$ & $50(75.8)$ \\
\hline Employment Status & Informal & $11(23.3)$ & $24(72.7)$ & $35(53)$ \\
\hline \multirow{2}{*}{ Knowing Computer } & A little & 24() & $25(75.8)$ & $49(74.2)$ \\
\hline & Primary & $9(27.3)$ & $8(24.2)$ & $17(25.8)$ \\
\hline \multirow{3}{*}{ Interesting to electronic education } & Low & $4(12.12)$ & $0(18.18)$ & $10(15.15)$ \\
\hline & Middle & $15(45.45)$ & $14(42.42)$ & $29(43.93)$ \\
\hline & High & $14(42.42)$ & $13(39.39)$ & $27(40.90)$ \\
\hline \multirow{2}{*}{ History of participation in educational program } & Yes & $2(6.1)$ & 0() & $2(3.0)$ \\
\hline & No & $31(93.9)$ & $33(100)$ & $66(96.9)$ \\
\hline
\end{tabular}

${ }^{\mathrm{a}}$ Values are expressed as No. (\%).

Table 2. Comparing of Knowledge Before and After Education in Each Group Workshop and Electronic

\begin{tabular}{|c|c|c|c|c|c|c|}
\hline \multirow[t]{2}{*}{ Variable } & \multicolumn{2}{|c|}{ Workshop } & \multicolumn{2}{|c|}{ Electronic } & \multirow[t]{2}{*}{$\mathbf{t}$} & \multirow[t]{2}{*}{ P Value } \\
\hline & Mean \pm SD & Confidence Interval & Mean \pm SD & Confidence Interval & & \\
\hline Before Intervention & $15.06 \pm 4.3$ & $13.16,85.26$ & $14.12 \pm 2.51$ & $13.15,23.01$ & -1.28 & 0.21 \\
\hline After Intervention & $20.21 \pm 2.74$ & $19.21,24.18$ & $20.88 \pm 2.88$ & $19.21,85.9$ & 0.96 & 0.34 \\
\hline
\end{tabular}

Table 3. Comparing the Effect of Electronic Method on Participants 'Attitude Before and After Education

\begin{tabular}{|c|c|c|c|c|c|c|}
\hline \multirow[t]{2}{*}{ Group } & \multicolumn{2}{|c|}{ Mean \pm SD } & \multicolumn{2}{|c|}{ Interval Confidence } & \multirow[t]{2}{*}{$\mathbf{t}$} & \multirow[t]{2}{*}{ P Value } \\
\hline & Before & After & Before & After & & \\
\hline Electronic & $34.24 \pm 4.86$ & $36.76 \pm 6.36$ & $32.35,51.96$ & $34.39,50.01$ & -2.16 & 0.04 \\
\hline
\end{tabular}

training using CD was providing brief and useful information relevant to target group, time and place (21).

According to the results of current study which indicates positive impact of using this training method (CD) on increasing knowledge and attitude of participants after intervention, it can be concluded that e-learning method by $C D$ can be used as a complementary or even an alternative method to replace traditional methods. In order to better conduct e-learning methods, personnel must be encouraged and well trained to use state-of-the-art technologies. Material used in this e-learning method was CD (text and slide). Thus, future studies on other electronic training methods and also in other fields of medical sciences are recommended to obtain more precise results. Limitations of this study were using CD for e-learning method and low number of participants.

\section{Acknowledgments}

The authors appreciate all personnel of midwifery working in health-care centers of Kerman, Ms. Batoul Abadiin charge of the mother caring program, midwifery personnel of Afzalipour hospital, especially Ms. Nosrat Darijani. This research is taken from MSc. thesis with the same title.

\section{Footnotes}

Conflict of Interest: To prevent the information on potential conflict of interest for authors from being overlooked 
or misplaced, mention this information in the cover letter. Authors must identify any potential financial conflicts of interest before the review process begins. Declared conflict of interest will not automatically result in rejection of paper but the editors reserve the right to publish any declared conflict of interest alongside accepted. The following would generally be regarded as potential conflicts of interest: 1. Direct financial payment to an author for the research or manuscript production by the sponsor of a product or service evaluated in an article. 2. Ownership of shares by an author in the company sponsoring a product service evaluated in an article (or in a company sponsoring a competing product). 3. Personal consultant for companies or other organizations with a financial interest in the promotion of particular health care products and services Authors' Contribution: Pooran Hadidi: design of study, intervention, data interpretation of data; Sakineh Sabzevari: design of study, statistical analysis, writing article; Ramin Homayoni Zand: study observation, cooperation in data interpretation.

\section{References}

1. Karimi M, Tavakol K, Alavi M. Comparition of Two Educational Methods of Lecture and Group Discussion on Learning and Reminding of Nursing Students. Sci J Hamadan Nurs Midwifery Faculty. 2006;13(2):1525.

2. Karami M, Ahanchian MR, Ebrahimi Kooshk Mahdi S. Barriers to use electronic courses of continuing medical education: A survey in Mashhad University of Medical Sciences. Iran J Med Education. 2012;12(5):377-86.

3. Hosseininasab D, Abdullahzadeh F, Feizullahzadeh $\mathrm{H}$. The effect of computer assisted instruction and demonstration on learning vital signs measurement in nursing students. Iran J Med Educ. 2007;7(1):2330.

4. Khatoni A, Dehghan Nayery N, Ahmady F, Haghani H. Comparison the Effect of Web-based Education and Traditional Education on Nurses Knowledge about Bird Flu in Continuing Education. Iran J Med Educ. 2011;11(2):140-7.

5. Khorami Rad A, Heidari A, Ahmari Tehran H. Comparison of Two Self-Learning Methods (CD-Rom or Booklet) for Physician Education about Reporting Diseases Cases. Iran J Med Educ. 2011;11(2):149-58.

6. Azizi F, Rezaei Ghale N, Riahi Asl N. Medical Education, Challenges and Prospects. Tehran: Vice Chancellor Student Affairs Ministry of Health and Medical Education;; 2003. pp. 607-9.

7. Alavi S, Shariati M. Investigating Employees Satisfaction with Elearning Courses in Tehran University of Medical Sciences. Iran J Med Educ. 2010;10(3):200-10.
8. Sung YH, Kwon IG, Ryu E. Blended learning on medication administration for new nurses: integration of e-learning and face-to-face instruction in the classroom. Nurse Educ Today. 2008;28(8):943-52. doi: 10.1016/j.nedt.2008.05.007. [PubMed: 18599162].

9. Zolfaghari M, Mehrdad N, Parsa Yekta Z, Salmani Barugh N, Bahrani N. The effect of lecture and e-learning methods on learning mother and child health course in nursing students. Iran J Med Educ. 2007;7(1):319.

10. Francescato D, Porcelli R, Mebane M, Cuddetta M, Klobas J, Renzi $P$. Evaluation of the efficacy of collaborative learning in face-to-face and computer-supported university contexts. Comput Human Behav. 2006;22(2):163-76. doi: 10.1016/j.chb.2005.03.001.

11. Fatahi Bafghi A, Karimi H, Anvari M, Barzegar K. Comparison the Effectiveness of Lecture and Discussion Group on Undergraduate Student Learning. Strides Dev Med Educ. 2007;4(1):51-6.

12. Hugenholtz NI, de Croon EM, Smits PB, van Dijk FJ, Nieuwenhuijsen K. Effectiveness of e-learning in continuing medical education for occupational physicians. Occup Med (Lond). 2008;58(5):370-2. doi: 10.1093/occmed/kqn053. [PubMed: 18495676].

13. Bahri N, Ghadivzadeh T, Bahri N. The Impact of Integrated Education on the Clinical Skills of Midwifery Midwives in Villages Participating in a Continuing Education Workshop. Strides Dev Med Educ. 2009;6(2):165-72.

14. Barbaz A, Zareiyan A. Comparison of three instructional methods for drug calculation skill in nursing critical care courses: lecturing, problem solving, and computer-assisted self-learning. Iran JMed Educ. 2012;12(6):420-9.

15. Emrani S, Fardanesh H, Abrahimzade E. Comparison of two Lecturebased Learning, e-Learning Model of Learning and Motivation Merrill and Reigluth Manpower. CME. 2012;9(2):143-52.

16. Vafamehr V. Comparing the Effectiveness of Two Educational Approaches of "Electronic Learning and Training in Small Groups" and" Training Only in Small Groups" in Teaching Physical Examination. Iran J Med Educ. 2010;10(1):11-8.

17. Zarif Sanaiey N, Karamizadeh Z, Faghihi AA, Mohammadi H. The comparison study of Knowledge and skill of physicians before and after contribution in traditional and electronic continuous Medical Education Diabetic course. Interdisciplinar J Virtual Learn Med Sci. 2012;3(1):21-30.

18. Meyer LH, Sternberger CS. Self-efficacy, self-reliance, and motivation in an asynchronous learning environment. World Acad Sci Engin Technol. 2005;8(4):225-9.

19. Al-Doub E, Goodwin R, Al-Hunaiyyan A. Students' Attitudes towards e-Learning in Kuwait's Higher Education Institutions 2009. Available from: http://oa.stellarnet.eu/openarchive/browse.

20. Latifnejad Roudsari R, Hosseini BL. Measuring students' knowledge and attitude towards E-learning in Mashhad University of Medical Sciences (MUMS). Iran J Med Educ. 2011;10(4):364-73.

21. Borhani F, Vatanparast M, Abbaszadeh A, Seyfadini R. The effect of training in virtual environment on nursing students attitudes toward virtual learning and its relationship with learning style. Iran J Med Educ. 2012;12(7):508-17. 